\title{
Reconstructive Plastic Surgery in a Single Lung Transplant Recipient: A Review of Perioperative Considerations
}

\section{Amy Tran E* and Lowry Cole E \\ Division of Plastic Surgery, University of Texas Medical Branch}

*Corresponding author: Ellen Amy Tran, Division of Plastic Surgery, University of Texas Medical Branch, 301 University Blvd Galveston, TX 77550, USA, Tel: 5125777509; E-mail: eatran@utmb.edu

\section{Case Report \\ Volume 2 Issue 1}

Received Date: December 04, 2017

Published Date: January 12, 2018

DOI: $10.23880 /$ ijtps- 16000109

\section{Abstract}

Background: The number of solid organ transplants as well as long term survival is increasing due to advancements in immunosuppression and technology. In 2016, there were 2,327 lung transplants performed in the United States. With the increase in solid organ transplant recipients (SOTRs), it has become more common to perform plastic and reconstructive surgery procedures on this unique population. Postoperative complications due to the complexity of these patients, especially for lung transplant recipients (LTRs), have not been well characterized.

Design: We report an elderly patient with multiple comorbidities, including single lung transplantation with contralateral pneumonectomy, who underwent multi-stage nasal tip reconstruction after mohs surgery for squamous cell carcinoma. We review the perioperative considerations and suggested guidelines for reconstructive surgery in immunocompromised lung transplant recipients, including a multidisciplinary conversation regarding cardiopulmonary clearance, management of immunosuppressive therapy, and careful postoperative observation and follow up.

Keywords: Lung Transplant; Immunosuppression; Squamous cell carcinoma; Mohs dermatologist; Nose

Abbreviations: SOTRs: Solid Organ Transplant Recipients; LTRs: Lung transplant recipients; OPTN: Organ Procurement and Transplantation Network; SCCs: Squamous Cell Carcinomas; VEGF: Vascular Endothelial Growth Factor.

\section{Introduction}

Due to significant advances in immunosuppression and transplant surgery, solid organ transplant recipients (SOTRs) are having longer and higher quality lives. In
2016 according to Organ Procurement and Transplantation Network (OPTN) data, there were a total of 33,610 solid organ lung transplants, within which there were 2,327 lung transplants. Due to the increased life expectancy, there have been more frequent and aggressive squamous cell carcinomas (SCCs) in this population requiring reconstruction by plastic surgeons. There is also an elevated risk imparted by increased age, white race, male sex, and thoracic organ transplantation [1]. The risk of skin malignancies in immunosuppressed transplant patients can be anywhere from 4 to 21 times greater than the general population, depending on levels of sunshine exposure, with the incidence of squamous cell 


\section{International Journal of Transplantation \& Plastic Surgery}

carcinomas increased between 65- and 250 fold greater than the general population $[2,3]$.

SOTRs have delayed and abnormal wound healing, depressed immune functions, nutritional, electrolyte and metabolic derangements that contribute to their susceptibility to SCCs. Immunosuppressive medications may accelerate the development of SCCs in SOTRs through 2 distinct mechanisms: the agents used in transplantation may be directly carcinogenic, and the chronic immunosuppression results in impaired immune surveillance and eradication of precancerous changes [4].

Thus, reconstructive surgeries in SOTRs are more risky than on the general population. However, some studies show that the complication prevalence in transplant patients who receive plastic surgery is overall $23.9 \%$ but can be as low as $6 \%$ in elective and $4 \%$ in cosmetic procedures [5]. In a study of hand, reconstructive, and cosmetic cases performed on 65 SOTRs (not including any LTRs) from 2004-2011, 14.4\% were found to have wound healing complications, $2.2 \%$ with bleeding, $2.2 \%$ with postoperative pain, and 1 death. $9 \%$ of these complications were from head and neck local flaps [6].

In light of minimal literature of reconstructive surgery or even any elective surgery in LTRs, this case report may shed light on some unique complications and perioperative considerations in this medically complex population [7-9]. There also is limited literature regarding success of paramedian forehead flap, septal lining flaps, and cartilage grafts in SOTRs $[10,11]$. Our case report involves some wound complications, but is overall a successful reconstructive result.

\section{Case Report}

The patient is a 70 year old male with significant past medical history of stage 1 small cell lung cancer on left lung resulting in recent left pneumonectomy, right single lung transplantation due to idiopathic pulmonary fibrosis in 2011, hypertension, congestive heart failure, coronary artery disease $\mathrm{s} / \mathrm{p}$ coronary artery bypass graft, diabetes mellitus with chronic kidney disease stage 3 , paroxysmal atrial fibrillation, hyperlipidemia, gastroesophageal reflux disease following laparoscopic Nissen fundoplication, multiple SCCs, who presented as a consult after mohs resection of a $1.5 \mathrm{~cm} \mathrm{x} 1.6 \mathrm{~cm}$ squamous cell carcinoma (SCC) on his nasal tip (Figure 1). The patient initially noted the mass approximately in January 2017. After it continued to grow, he saw a dermatologist close to his home for biopsy on $7 / 19 / 2017$. He was then referred to and seen by our mohs surgeon on 8/15/17 for excision, and reconstruction was performed in 3 stages. The first stage occuring on $8 / 15 / 17$, second stage on $9 / 19 / 17$ and final stage on $10 / 24 / 17$.The final defect after mohs surgery was $3.2 \mathrm{~cm} \times 3.1 \mathrm{~cm}$ with depth including cartilage and nasal mucosa (Figure 2). Decision was made to reconstruct the lining, structure, and soft tissue defects with bilateral septal lining flaps, cartilage grafts from the septum and the right ear, and a paramedian forehead flap $[12,13]$.
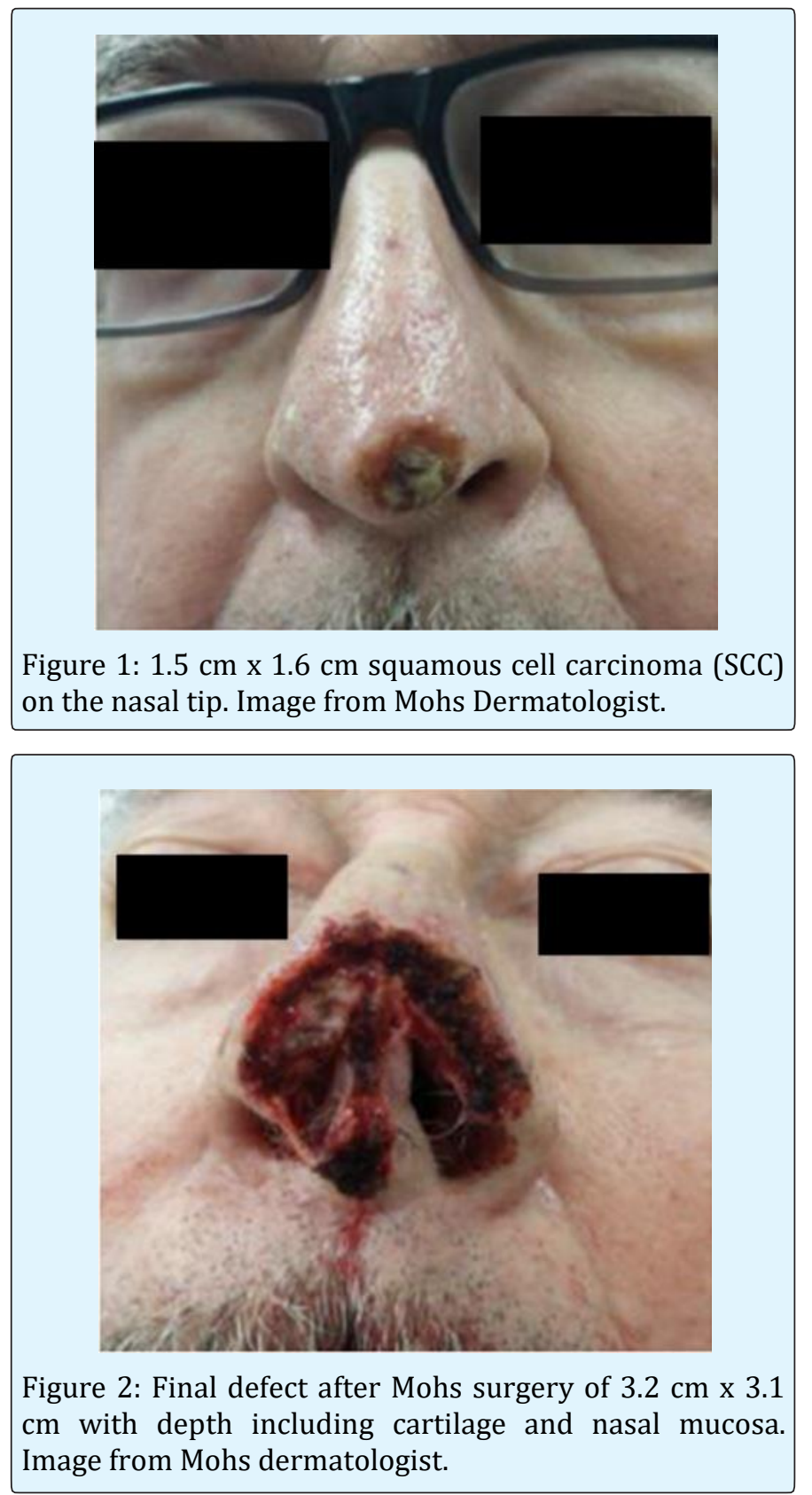

Preoperative assessment by cardiothoracic anesthesia and his cardiologist was completed. Anticoagulation of 


\section{International Journal of Transplantation \& Plastic Surgery}

elliquis and aspirin was stopped a week prior to surgery. $\mathrm{He}$ continued the remainder of his home medications including immunosuppression of tacrolimus $2 \mathrm{mg}$ PO BID, sirolimus $1 \mathrm{mg}$ PO qhs, and prednisone $10 \mathrm{mg}$ daily, and PCP prophylaxis with bactrim weekly and azithromycin for treatment of chronic allograft dysfunction. He was deemed optimized for surgery. The operation consisted of surgical preparation with re-excision of eschar and necrotic skin, subcutaneous tissue, muscle and fascia and cartilage, throughout the entire $5 \times 5 \mathrm{~cm}$ wound, right paramedian forehead flap to nose, right intranasal axial fasciocutaneous septal lining flap, based on the right septal artery, left intranasal axial fasciocutaneous septal lining flap, based on left septal artery, right ear cartilage graft to nose, septal cartilage and bone graft to nose, xenograft placement, $4 \times 6 \mathrm{~cm}$ epidermal coverage to back of paramedian forehead flap stalk, and xenograft bolster to right ear (Figure 3). Total operative time was $4 \mathrm{hr}$ and 47 min. It was completed successfully with general anesthesia of propofol and remifentanil, without complication. Oral packing removed and oral gastric tube was passed with stomach suctioned of blood. The patient was extubated and following commands with adequate tidal volume in the operating room.

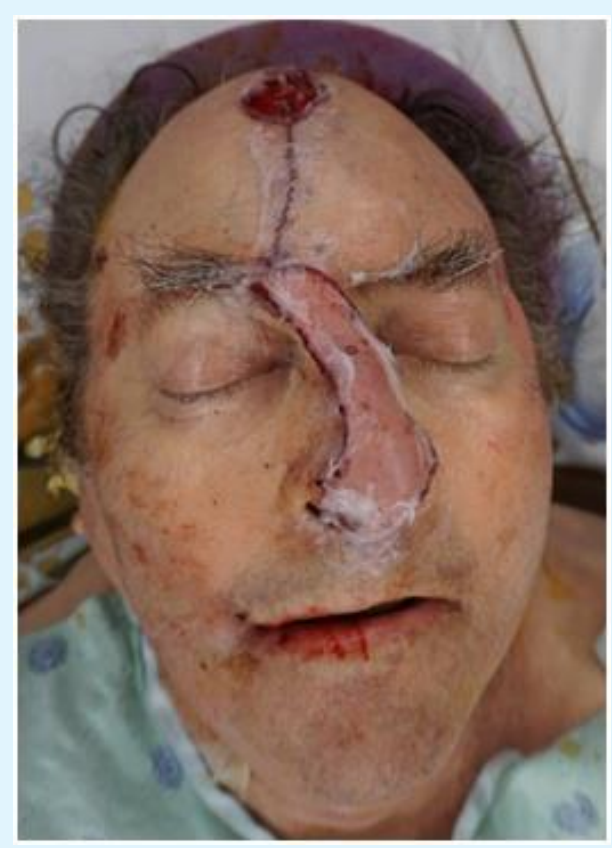

Figure 3: Immediately Post-operative from surgical preparation with re-excision of eschar and necrotic skin, subcutaneous tissue, muscle and fascia and cartilage, throughout the entire $5 \times 5 \mathrm{~cm}$ wound, right paramedian forehead flap to nose, right intranasal axial fasciocutaneous septal lining flap, based on the right septal artery, left intranasal axial fasciocutaneous septal lining flap, based on left septal artery, right ear cartilage graft to nose, septal cartilage and bone graft to nose, xenograft placement, $4 \times 6 \mathrm{~cm}$ to back of paramedian forehead flap stalk, and xenograft bolster to right ear.

Immediately postoperatively in the recovery unit, the patient had persistent bleeding from the nose and difficulty clearing secretions. Suctioning and duoneb administered with minimal improvement in sp02 77$82 \%$, with patient becoming increasingly tachypneic and increased work of breathing. Noninvasive ventilation would have compromised the flap so re-intubation was performed. Bronchoscopy was performed with several clots removed. SpO2 immediately improved to $100 \%$. Decision was made to continue intubation for 3 days to protect airway from continued surgical site bleeding. OG tube was placed to prevent aspiration. Post operatively, he received his home medications except Elliquis, ASA, and Sirolimus. For perioperative prophylaxis, he was given unasyn IV, and mupirocin ointment to suture lines. 1 unit of packed red blood cells was given for an acute decrease in hemoglobin from 8.5 to 7.7 on postoperative day 2 (POD2), afterwhich he remained at a baseline hemoglobin of approximately 9 for the duration of his hospitalization. He was extubated POD3 without complication. A few days post extubation, he developed ICU delirium which quickly resolved. $\mathrm{SQH}$ was started POD7. Elliquis and ASA were restarted POD8. He was ready for discharge POD7 but remained inpatient until POD14 due to Hurricane Harvey preventing travel in the area to his home that is 6 hours away. On discharge, the paramedian forehead flap and septal lining flaps were clean, dry, and intact, and well perfused without concern for ischemia or congestion.

One month postoperatively, he was seen in plastic surgery clinic. At that time the left intranasal flap was torn and partially necrotic. He had been itching his left nostril with his finger. Decision was made to return to the operating room for debridement the next day with post op admission for airway monitoring. Debridement of necrotic mucosa of nasal lining flaps and underlying exposed cartilage and with readvancement was done. There were no complications and he was discharged POD1. Second stage paramedian forehead flap inset was planned for the next month.

Patient was taken back 2 months after the initial surgery for final division and inset of paramedian forehead flap at nose, and forehead adjacent tissue transfer flaps, less than $10 \mathrm{sq} \mathrm{cm}$. Patient was discharged the same day with no complication and appropriate nasal tip contour. He resumed sirolimus around 6 weeks after 


\section{International Journal of Transplantation \& Plastic Surgery}

surgery. Recent postoperative photos show appropriate coverage (Figure 4).

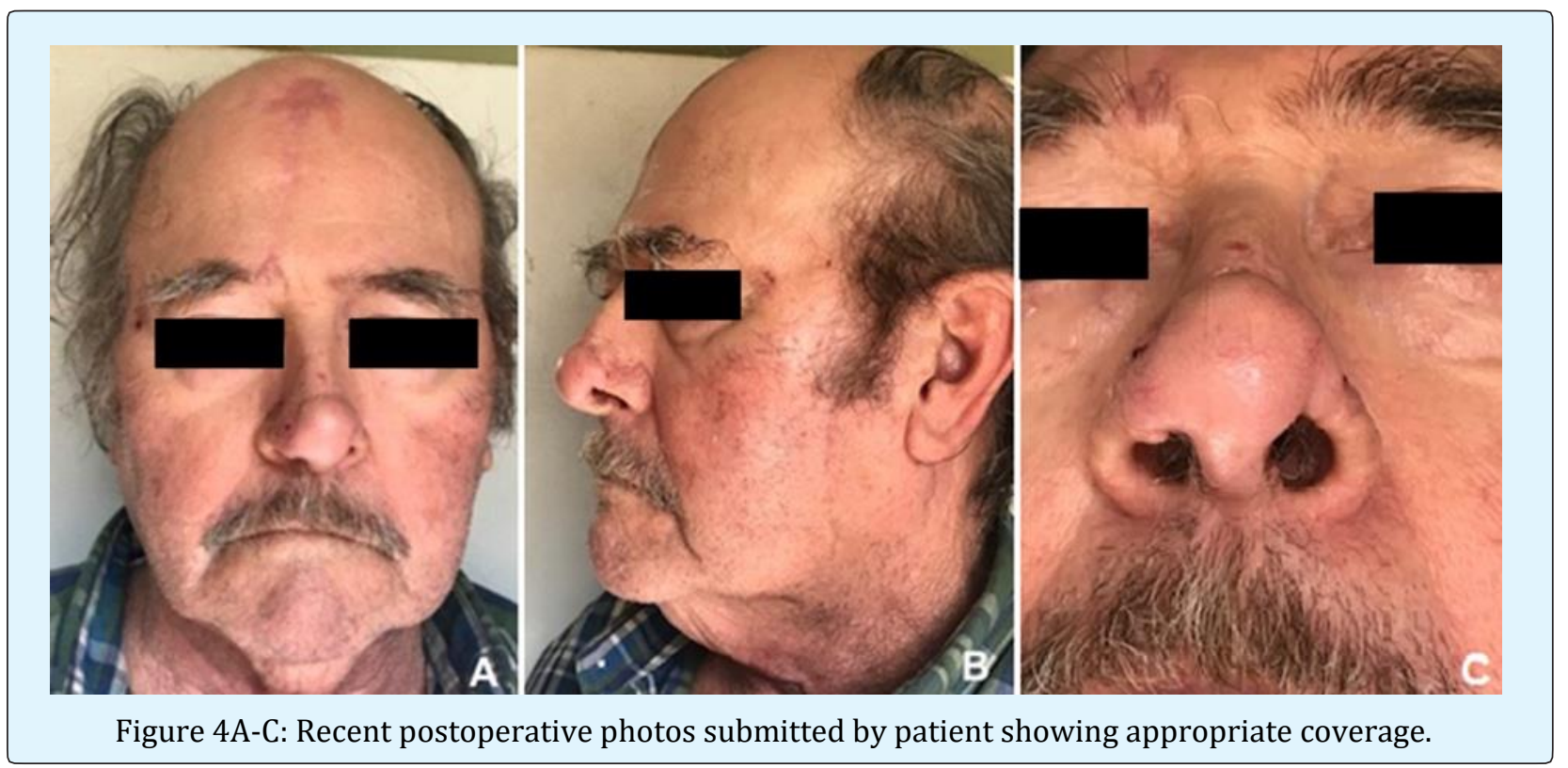

\section{Discussion}

As reviewed in the literature, it is fairly uncommon to have a contralateral pneumonectomy after single lung transplant, much less to also have a staged nasal reconstruction surgery [14]. Although there are a few articles highlighting suggested guidelines for elective surgeries in kidney and liver patients, there is minimal literature written on guidelines specifically for perioperative management of elective reconstruction in lung transplant patients. Limitations to this study include small sample size inherent to a case report study and minimal literature published for review.

Our complications from this case report included nasal lining flap trauma and necrosis, partial cartilage graft exposure and necrosis, and postoperative bleeding resulting in reintubation and admission to the surgical intensive care unit. In reflection of this experience, the authors have suggested guidelines for reconstructive surgery in lung transplant patients.

\begin{tabular}{|c|c|c|}
\hline Preoperative & Operative & Postoperative \\
\hline $\begin{array}{l}\text { - medical optimization from } \\
\text { multidisciplinary team } \\
\text {-cardiothoracic anesthesia } \\
\text { assessment } \\
\text { - immunosuppression reduction } \\
\text { - establish patient goals for } \\
\text { reconstruction } \\
\text { - optimize timing for best wound } \\
\text { healing potential }\end{array}$ & $\begin{array}{l}\text { - minimize length of procedure } \\
\text {-careful technique, meticulous } \\
\text { hemostasis } \\
\text { •consideration of longer lasting } \\
\text { suture and dressing } \\
\text { - euvolemia } \\
\text { - regional anesthesia when possible } \\
\text { - avoidance of anxiolytics that may } \\
\text { blunt respiratory drive }\end{array}$ & $\begin{array}{l}\text {-vigilant airway monitoring } \\
\text { - pulmonary hygeine } \\
\text { - observe for adrenal insufficiency } \\
\text { - anticipate longer tissue } \\
\text { immobilization and increased } \\
\text { likelihood of wound breakdown } \\
\text { - frequent multidisciplinary follow } \\
\text { up and surveillance }\end{array}$ \\
\hline
\end{tabular}

\section{Preoperative Medical Clearance}

Firstly, obtain clearance and maintain involvement from all teams. In this case, cardiology, pulmonology, dermatology, anesthesiology, and transplant surgery. 


\section{International Journal of Transplantation \& Plastic Surgery}

Assess patient's immunotherapy needs and if possible, reduce immunotherapy if possible. In our case, to stop sirolimus after surgery for 6 weeks to prevent wound complications. Multiple studies have shown that this inhibitor of cell signal transduction and proliferation is related to high rates of wound complications by impairing wound healing, by reducing wound-breaking strength, decreasing wound collagen deposition and expression of Vascular Endothelial Growth Factor (VEGF) and Nitric Oxide in wounds [15]. Tacrolimus was also shown to impair wound healing by the same mechanisms of reducing wound-breaking strength, collagen deposition, and nitric oxide and nitric oxide synthase expression. Corticosteroids are known to inhibit all phases of wound repair [4].

The timing of surgery is also critical for allowing the most opportune wound healing. It is best to avoid the period immediately post-transplant, a time of greatest immunosuppression where the patient is most at risk for infection and poor wound healing [8]. This time is also important to avoid specifically because LTRs often require several months before they reach their peak expected lung capacity [14]. Also a thorough preoperative evaluation to evaluate functional capacity (exercise capacity, need for supplemental oxygen) and any possible lung dysfunction or infection (presence of symptoms such as dyspnea, fatigue, fevers, or sputum production) should be done prior to elective surgery. Any suggestion of deterioration should delay all non-emergent surgery until both rejection and infection can be excluded.

Additionally, for patients on chronic low dose steroids (5-10 prednisone per day), the literature does not support use of stress doses for the majority of procedures [8]. It is suggested to use their usual dose of corticosteroids. If patient have symptoms of adrenal insufficiency, give additional peak steroid doses every 8 hours over a few days.

Finally, choose a surgical technique for reconstruction that is best for the defect, immunosuppressed patient, and their goals. For example in our case, for the soft tissue coverage, we chose a paramedian forehead flap due to its robust blood supply, keeping in mind possibilities of delayed wound healing, and that it is gold standard for nasal tip defects of this size [13]. Other options of skin graft and healing by secondary intention were considered but not pursued due to the large size and depth of the defect and delayed wound healing expected in a immunosuppressed patient.

\section{Operative Considerations}

Perioperative antibiotics should be dosed per normal guidelines recommended by the national surgical infection prevention project. The literature available does not support more extensive antibiotic protocols in immunosuppressed patients [8].

Length of procedures should be minimized in the setting of diminished reserve of transplanted organs. Lung transplantation also results in disruption of the pulmonary lymphatics and bronchial circulation, leading to an increased risk of pulmonary edema. Fluid management should be conservative in the perioperative setting and diuretics prescribed if necessary [8].

It is also critical to request a cardiothoracic anesthesiologist who is aware of the possibility for altered upper airway anatomy. Caution should be taken towards use of anxiolytic preoperative medications that may blunt the respiratory drive. A regional anesthesia technique would be preferable to general anesthesia whenever possible to decrease the risk of airway trauma and aspiration.

Oral packing should also be used to prevent blood accumulation in the GI system and airway. An oral gastric tube should be passed to remove any blood that may cause emesis. Continuing intubation postoperatively should also be considered in the setting of nasal bleeding that may compromise your limited respiratory capacity.

Flawless operative technique is important for a successful outcome, including complete debridement, hemostasis, and gentle handling of tissues. One should consider longer lasting sutures and dressings to account for delayed wound healing. It is preferable to use nonabsorbable or long-lasting synthetic monofilament absorbable sutures to maintain adequate tensile strength for a longer period of time [7].

Finally, it is pertinent to choose a reconstructive option that is in alignment with the patient's desires, goals, commitment, and responsibility.

\section{Postoperative Management}

It is pertinent to maintain careful monitoring of the airway and to consider remaining intubated until postoperative bleeding has concluded. Many physiologic changes have been observed following lung transplantation that may impact the outcomes of subsequent surgeries. In bilateral LTRs, the carinal receptors are not intact, resulting in diminished or 


\section{International Journal of Transplantation \& Plastic Surgery}

nonexistent cough reflex. In bilateral and single LTRs, mucociliary transport is also impaired and airway hyper responsiveness leading to bronchospasm is common [14]. Thus perioperative pulmonary hygiene, incentive spirometry, chest physiotherapy, and secretion mobilization, is of upmost importance.

Postoperative immobilization should be applied for twice as long as the general population to account for longer duration of healing time. 7Frequent postoperative follow up of the surgical site is necessary for early identification of infection, wound healing issues, and encouraging patient compliance.

Finally, it is critical to maintain communication with all teams involved and ensure follow ups for immunosuppression therapy management, comorbidity management, and surveillance.

\section{Conclusion}

Improvements in the post-transplant immunosuppression regimen have permitted transplant recipients to live longer lives and as a result, experience more SCCs requiring excision and at times extensive reconstruction. In our case of a post-lung transplant and single lung patient with aggressive SCC requiring reconstruction of the lining, structure, and soft tissue domain of the nasal tip, we have encountered complications unique to this situation. In the context of this experience, we have reviewed the literature and encountered minimal perioperative guidelines. In reflection, we have outlined some suggestions in regards to perioperative management of reconstruction in lung transplant patients.

\section{Acknowledgments}

The authors wish to thank the patient and his family for their consent to publish this case report, as well as the support of our colleagues involved in his case.

\section{References}

1. Garrett GL, Blanc PD, Boscardin J, Lloyd AA, Ahmed RL, et al. (2017) Incidence of and Risk Factors for Skin Cancer in Organ Transplant Recipients in the United States. JAMA Dermatol 153(3): 296-303.

2. Berg D, Otley CC (2002) Skin cancer in organ transplant recipients: Epidemiology, pathogenesis, and management. J Am Acad Dermatol 47(1): 1-17.
3. Euvrard S, Kanitakis J, Claudy A (2003) Skin cancers after organ transplantation. N Engl J Med 348(17): 1681-1691.

4. Ulrich C, Arnold R, Frei U, Hetzer R, Neuhaus P, et al. (2014) Skin changes following organ transplantation: an interdisciplinary challenge. Dtsch Arztebl Int 111: 188-194.

5. Cohen M, Pollak R, Garcia J, Mozes MF (1989) Reconstructive surgery for immunosuppressed organ-transplant recipients. Plast Reconstr Surg 83(2): 291-295.

6. Elizabeth Z, Rachel L, Carolyn C, Derek S (2016) Complications Following Plastic Surgery in Solid Organ Transplant Recipients: A Descriptive Cohort Study. Journal of Aesthetic \& Reconstructive Surgery 2: 10 .

7. Dunda SE, Bozkurt A, Pallua N, Krapohl BD (2015) Reconstructive surgery in immunocompromised patients: evaluation and therapy. GMS Interdiscip Plast Reconstr Surg DGPW 4: Doc18.

8. Gohh RY, Warren G (2006) The preoperative evaluation of the transplanted patient for nontransplant surgery. Surg Clin North Am 86(5): 1147-1166.

9. Randle HW (2009) Surgical intervention for skin cancer in organ transplant recipients. Cancer Treat Res 146: 433-438.

10. Miller MW, Dean NR, Cannady SB, Rosenthal EL, Wax MK (2012) Free tissue transfer for head and neck reconstruction in solid organ transplant patients. Head Neck 34(8): 1143-1146.

11. Sweis I, Tzvetanov I, Benedetti E (2009) The new face of transplant surgery: a survey on cosmetic surgery in transplant recipients. Aesthetic Plast Surg 33(6): 819826.

12. Correa BJ, Weathers WM, Wolfswinkel EM, Thornton JF (2013) The forehead flap: the gold standard of nasal soft tissue reconstruction. Semin Plast Surg 27(2): 96-103.

13. Sanniec K, Malafa M, Thornton JF (2017) Simplifying the Forehead Flap for Nasal Reconstruction: A Review of 420 Consecutive Cases. Plast Reconstr Surg 140(2): 371-380. 


\section{International Journal of Transplantation \& Plastic Surgery}

14. Fitton TP, Bethea BT, Borja MC, Yuh DD, Yang SC, et al. (2003) Pulmonary resection following lung transplantation. Ann Thorac Surg 76(5): 1680-1685.
15. Schäffer M, Schier R, Napirei M, Michalski S, Traska T, et al. (2007) Sirolimus impairs wound healing. Langenbecks Arch Surg 392(3): 297-303. 